\title{
A Software Package and Hardware Tools for in situ Experiments in a Lagrangian Reference Frame
}

\author{
Andrea M. Doglioli, Francesco Nencioli, Anne A. Petrenko, and Gilles Rougier \\ Aix Marseille Université, CNRS/INSU, IRD, Mediterranean Institute of Oceanography, UM 110, Marseille, and Université du Sud \\ Toulon-Var, CNRS/INSU, IRD, Mediterranean Institute of Oceanography, UM 110, La Garde, France \\ JEAN-LUC FUDA \\ IRD, US191 IMAGO, Nouméa, New Caledonia
}

NICOLAS GRIMA

Laboratoire de Physique des Océans, UMR 6523, CNRS-IFREMER-IRD-UBO, Brest, France

(Manuscript received 22 August 2012, in final form 18 April 2013)

\begin{abstract}
The Lagrangian Transport Experiment (LATEX) was developed to study the influence of coupled physical and biogeochemical dynamics at the meso- and submesoscales on the transfers of matter and heat between the coastal zone and the open ocean. One of the goals of the Latex10 field experiment, conducted during September 2010 in the Gulf of Lion (northwest Mediterranean), was to mark a dynamical mesoscale feature by releasing a passive tracer [sulfur hexafluoride $\left(\mathrm{SF}_{6}\right)$ ] together with an array of Lagrangian buoys. The goal was to release the tracer in an initial patch as homogeneous as possible in the horizontal, and to study its turbulent mixing and dispersion while minimizing the contribution due to advection. For that, it was necessary to continuously adjust the vessel route in order to remain as closely as possible in the Lagrangian reference frame moving with the investigated mesoscale structure. To accomplish this task, a methodology and software were developed, which are presented here. The software is equipped with a series of graphical and user-friendly accessories and the entire package for MATLAB can be freely downloaded (http://mio. pytheas.univ-amu.fr/ doglioli).
\end{abstract}

\section{Introduction}

The importance of a Lagrangian sampling strategy for the analysis of tracer dispersion has been evidenced by pioneer studies within the Iron Enrichment Experiment (IronEx), the first in situ iron-enrichment experiment (Law et al. 1998; Stanton et al. 1998). In fact, only the measurements collected in a Lagrangian reference frame moving with a tracer patch allow to correct the tracer budget for the effect caused by water advection, and thus permit its accurate estimation. The Lagrangian-based navigation system developed for IronEx has been briefly described by Coale et al. (1998). Their system was used

\footnotetext{
Corresponding author address: Andrea M. Doglioli, Aix-Marseille Université, Mediterranean Institute of Oceanography, Campus de Luminy, Case 901, 13288 Marseille CEDEX 9, France.

E-mail: andrea.doglioli@univ-amu.fr
}

during the tracer release to correct the ship route with respect to the current drift in order to introduce in the environment an initial patch as square as possible in the horizontal. The center of the Lagrangian reference frame was defined by the position of a drogued buoy deployed before the tracer release. The buoy was equipped with a global positioning system (GPS) receiver connected to a very high-frequency (VHF) packet radio transmitter. An onboard VHF receiver was interfaced with a computer. A specific software was developed in order to display the ship and buoy positions overlaid to the injection (or sampling) grid.

Release and tracking of a tracer patch within a Lagrangian reference frame was also at the base of the Plankton Reactivity in the Marine Environment (PRIME) project (Law et al. 2001). During the field experiment, an eddy was marked with Argos buoys and a passive tracer [sulfur hexafluoride $\left(\mathrm{SF}_{6}\right)$ ] was released in a Lagrangian 
framework using a dead-reckoning strategy. Such strategy included corrections for surface-water advection: the projected ship trajectory was adjusted according to the ship-recorded surface current measurements in order to release the tracer following the same water mass. One major disadvantage of dead reckoning is that, between successive known positions, or fixes, the ship trajectory adjustments are estimated using only previously recorded information, kept constant in time. Errors and uncertainties are thus cumulative and tend to grow with time, limiting the accuracy of such strategy. Hence, subsequent in situ Lagrangian release experiments, such as the Southern Ocean Iron Release Experiment (SOIREE; Boyd and Law 2001), the Carbon Cycle Linkages of Permafrost Systems (CYCLOPS; Law et al. 2005), the Subarctic Pacific Iron Experiment for Ecosystem Dynamics Study (SEEDS; Tsumune et al. 2005), and the second SEEDS (SEEDS II; Tsumune et al. 2009), were all performed, adopting the older technique first developed for the IronEx project (Law et al. 1998). Minor modifications to this strategy were then implemented within the Subarctic Ecosystem Response to Iron Enrichment Study (SERIES) experiment (Law et al. 2006), during which the Lagrangian tracer release was coordinated using the Electronic Chart Precise Integrated Navigation System (ECPINS) package. This is a commercial search and rescue computerized package for shipboard navigational aid that displays electronic charts and the ship's position in real time along with sensor data (http:// osigeospatial.com/offshoresystems/pdf/OSI_ECPINS5000.pdf). To our knowledge, no other papers report detailed descriptions of the techniques and software adopted for Lagrangian tracer release and sampling strategy, although they are a key point for the success of in situ tracer experiments.

In this article we will describe the methodological approach and the technological advances (hardware and software) developed during the Lagrangian Transport Experiment (LATEX) project (2008-10; http://www.com. univ-mrs.fr/LOPB/LATEX). LATEX was designed to study the influence of the coupled physical and biogeochemical dynamics at the meso- and submesoscales on the transfers of matter and heat between the coastal zone and the open ocean. To reach this goal, the project was highly multidisciplinary, with a strategy based on a combined use of satellite data, numerical model results, and in situ measurements from a series of four field campaigns. The main goal of the field experiment was to analyze transport patterns and dispersion rates of a mesoscale structure within the Lagrangian reference frame associated with it. Therefore, the experiment was designed to combine the release of $\mathrm{SF}_{6}$ with the deployment of an array of Lagrangian buoys. Two of the four LATEX field campaigns were dedicated to the tracer release experiment. The first one, the Latex00 campaign (9-11 June 2007), was part of a pilot project that aimed to demonstrate the feasibility of our methodology. During the last one, the Latex10 campaign (1-24 September 2010), we first tested, and then successfully performed, the tracer release. The LATEX field campaigns were conducted in the Gulf of Lion (Fig. 1). This region is particularly appropriate for studying coastal mesoscale dynamics and its role in cross-shelf exchanges. In fact, exchanges between the Gulf of Lion and offshore waters are mainly induced by processes associated with the Northern Current (Conan and Millot 1995; Flexas et al. 2002; Petrenko et al. 2005). The Northern Current is an alongslope density current that exhibits an important mesoscale activity induced by (i) topographical forcing, (ii) interaction with the strong northerly and northwesterly winds (mistral and tramontane), and (iii) presence of the Rhône River freshwater discharge (e.g., Schaeffer et al. 2011, and references therein).

On the basis of a 10-yr realistic simulation from a high-resolution numerical model ( $\mathrm{Hu}$ et al. 2009, 2011a; Campbell et al. 2013), the western part of the Gulf of Lion was chosen to be investigated by two exploratory campaigns, Latex08 (1-5 September 2008) and Latex09 (2428 August 2009). The results of both campaigns evidenced the presence of anticyclonic eddies at the end of the summer (Hu et al. 2011b; Kersalé et al. 2013). For this reason, the Latex10 cruise was organized in the same region during the same period of the year. Finally, the area for the tracer dispersion experiment was selected, combining the numerical model results with the results from near-real-time analysis of finite-size Lyapunov exponents computed from both satellite-altimetry-derived currents and iterative releases of subsurface drifters (Nencioli et al. 2011).

Our Lagrangian strategy presents some important technological improvements with respect to previous tracer studies. In this paper, we intend to evidence the advancements leading to an increased accuracy in the Lagrangian navigation. Furthermore, we also announce the first release of a free software package dedicated to the application of our methodology.

\section{Background}

The budget of a given tracer can be described by the continuity equation for its concentration $\psi$, expressed as

$$
\frac{d}{d t} \int_{V} \psi d V+\oint_{S} \psi \mathbf{v} \cdot d \mathbf{S}+\oint_{S} \boldsymbol{\chi} \cdot d \mathbf{S}+\int_{V} \xi d V=0 .
$$

The temporal variation of $\psi$ in the volume $V$ (first term) is balanced by the variations across the volume surface $S$ (with $\mathbf{S}$ the vector area) caused by the advection by the current field $\mathbf{v}$ (second term) and other surface exchanges $\chi$ (third term), and by the sources and sinks $\xi$ 


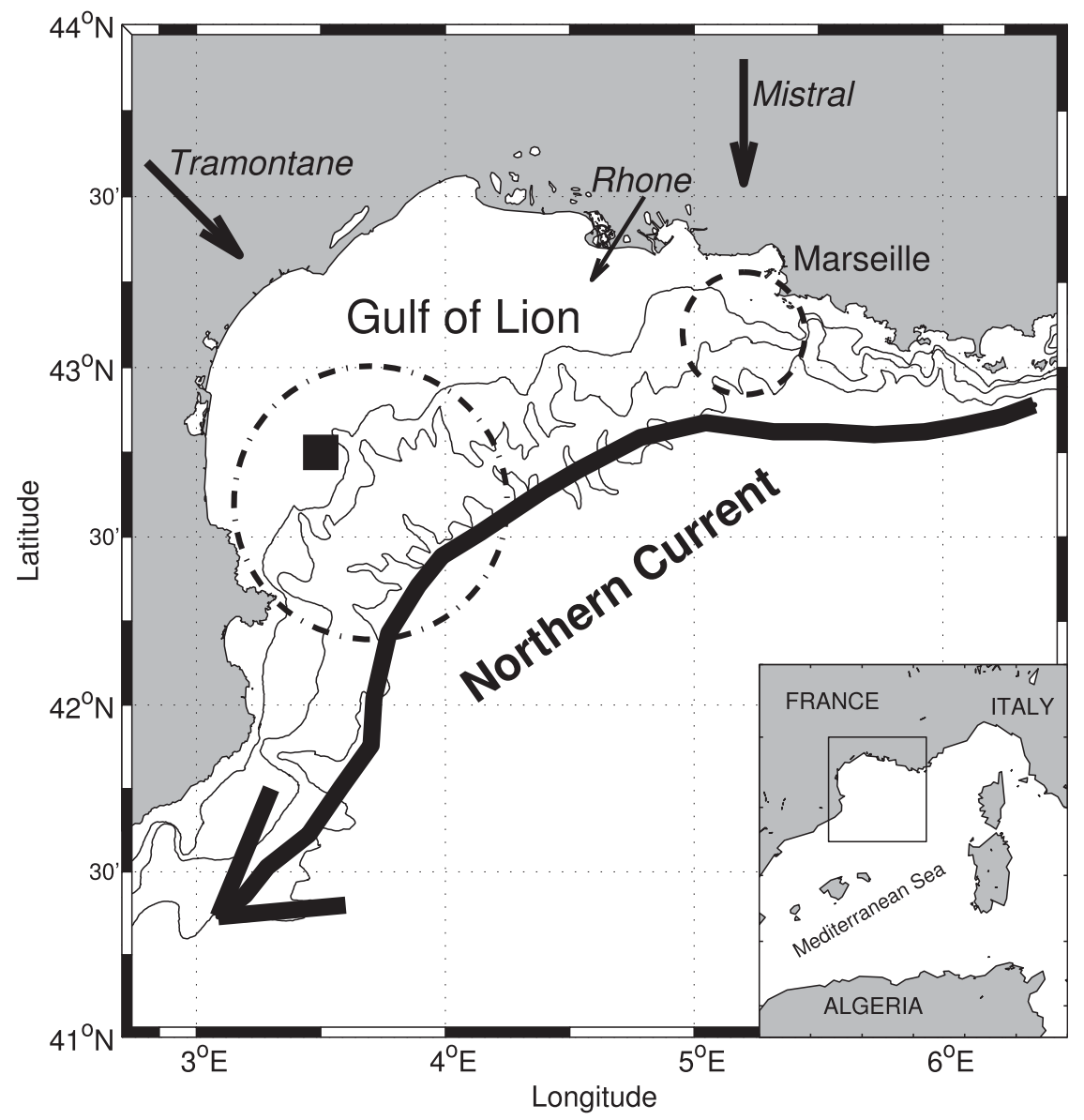

FIG. 1. Bathymetry of the Gulf of Lion (isobaths 100, 200, and $1000 \mathrm{~m}$ ). Arrows represent the Northern Current, the mistral and tramontane winds, and the Rhône River freshwater discharge. Dotted-dashed (dashed) circle shows the area of the Latex10 (Latex00) cruise. Black square shows the tracer release area.

within $V$ (fourth term). Using a Lagrangian reference frame to investigate a tracer budget is particularly advantageous, because the second term of Eq. (1) becomes null. Moreover, if the budget is derived for a conservative tracer as the $\mathrm{SF}_{6}$, then the fourth term also becomes null. Thus, when the two conditions mentioned above are fulfilled, it becomes possible to estimate $\chi$ by measuring the temporal variation only. In the ocean, for dissolved material or particles small enough to have negligible settling velocity, such $\boldsymbol{\chi}$ are the fluxes due to the vertical and horizontal turbulent mixing [e.g., Hillmer and Imberger (2007), for the case of a cylindrical volume]. Being properties of the flow, $\chi$ can be considered identical for both conservative and nonconservative tracers. Therefore, by using a Lagrangian reference frame and retrieving the turbulent fluxes from the budget of a conservative tracer, it is possible to estimate the sources and sinks of other nonconservative (i.e., biogeochemical) tracers by simultaneously measuring their temporal variation.
The approach described above has been adopted during the Latex10 cruise. A key aspect of the in situ experiment has been to plan in real time the ship route in the Lagrangian reference frame for the release of the conservative tracer and the successive samplings. Generally, a route is characterized by a number of "turn points," which are the positions at which a new direction is taken to reach the following turn point. In a Lagrangian reference frame, the position of each turn point moves with the water mass under investigation. Thus, it is necessary to continuously adjust the ship route toward the moving turn points. This is achieved using a classical ballistic approach under the following assumptions:

(i) ship speed is constant and faster than the buoy speed and

(ii) there is no stirring and no rotation associated with the investigated water mass.

The first assumption can easily be respected during a field experiment with a modern research vessel. Some attention 
has to be given to the design of the tracer release system in order to allow a release rate fast enough not to pose limitations to the ship speed in case the experiment is planned in very energetic regions. The second assumption may appear severe. However, unlike advection, stirring and rotation can be considered slow processes with respect to the tracer release or sampling. Estimating stirring and rotation would be possible by releasing at sea a large number of buoys, but it would significantly increase the cruise costs. We numerically tested the validity of such an assumption with a simple Lagrangian random-walk model. By using idealized current fields, we performed several comparisons on the resulting concentrations with and without stirring and rotation. Our numerical results confirmed the validity of this second assumption. ${ }^{1}$ Therefore, in the present work, just as in previous tracer experiments at sea, we also adopted it.

We use the following definitions:

(i) $\mathbf{v}_{\text {vessel }} \equiv\left(u_{\text {vessel }}, v_{\text {vessel }}\right)$ as the vessel speed. Its modulus during LATEX experiments was kept as constant as possible [in our case $3 \mathrm{kt}\left(1 \mathrm{kt}=0.51 \mathrm{~m} \mathrm{~s}^{-1}\right)$ for technical reasons associated with the $\mathrm{SF}_{6}$ release system] and

(ii) $\mathbf{v}_{\text {target }} \equiv\left(u_{\text {target }}, v_{\text {target }}\right)$ as the drift speed of a turn point $\left(x_{\text {target }}, y_{\text {target }}\right)$ of the route. It is assumed to be equal to the drift speed of a buoy released at the point of departure to mark the center of the water mass. This buoy (reference buoy) represents the moving origin of the Lagrangian reference frame.

We need to solve the following closed equation system:

$$
\begin{aligned}
& x_{\text {vessel }}+u_{\text {vessel }} t=x_{\text {target }}+u_{\text {target }} t, \\
& y_{\text {vessel }}+v_{\text {vessel }} t=y_{\text {target }}+v_{\text {target }} t, \quad \text { and } \\
& u_{\text {vessel }}^{2}+v_{\text {vessel }}^{2}=\left|\mathbf{v}_{\text {vessel }}\right|^{2} .
\end{aligned}
$$

The above system can be reduced to the following quadratic equation in time:

$$
a t^{2}+b t+c=0
$$

where

$$
\begin{aligned}
& a=u_{\text {target }}^{2}+v_{\text {target }}^{2}-\left|\mathbf{v}_{\text {vessel }}\right|^{2}, \\
& b=2\left[\left(x_{\text {target }}-x_{\text {vessel }}\right) u_{\text {target }}+\left(y_{\text {target }}-y_{\text {vessel }}\right) v_{\text {target }}\right], \text { and } \\
& c=\left(x_{\text {target }}-x_{\text {vessel }}\right)^{2}+\left(y_{\text {target }}-y_{\text {vessel }}\right)^{2} .
\end{aligned}
$$

Excluding the trivial case in which vessel and buoy are both at rest and positioned at the same point, the discriminant of Eq. (3) is always strictly positive. In fact, $c>0$ and, under the above-mentioned second assumption (vessel speed faster than buoy speed), $a<0$. Therefore, in case of practical oceanographic applications, Eq. (3) admits two real solutions that are always of opposite sign. The time required for the vessel to reach the target $\hat{t}$ is thus the positive solution. With $\hat{t}$, we can estimate the updated vessel velocity $\left(\hat{u}_{\text {vessel }}, \hat{v}_{\text {vessel }}\right)$ as

$$
\begin{aligned}
& \hat{u}_{\text {vessel }}=\frac{\left(x_{\text {target }}-x_{\text {vessel }}\right)}{\hat{t}}+u_{\text {target }} \text { and } \\
& \hat{v}_{\text {vessel }}=\frac{\left(y_{\text {target }}-y_{\text {vessel }}\right)}{\hat{t}}+v_{\text {target }}
\end{aligned}
$$

which, in turn, provides the distance between the vessel and the turn point

$$
\hat{d}=\sqrt{\left(\hat{u}_{\text {vessel }}\right)^{2}+\left(\hat{v}_{\text {vessel }}\right)^{2}} \hat{t}
$$

and the updated direction of the vessel (angle $\hat{\alpha}$ in relation to the north) that takes into account the drift of the water mass

$$
\hat{\alpha}=\left\{\begin{array}{lll}
90^{\circ}-\arctan \left(\hat{v}_{\text {vessel }} / \hat{u}_{\text {vessel }}\right) & \text { for } \hat{u}_{\text {vessel }}>0, & \\
180^{\circ} & \text { for } \hat{u}_{\text {vessel }}=0 \text { and } \hat{v}_{\text {vessel }}<0, \\
0^{\circ} & \text { for } \hat{u}_{\text {vessel }}=0 \text { and } \hat{v}_{\text {vessel }}>0, \text { and } \\
270^{\circ}-\arctan \left(\hat{v}_{\text {vessel }} / \hat{u}_{\text {vessel }}\right) & \text { for } & \hat{u}_{\text {vessel }}<0,
\end{array}\right.
$$

with $\arctan \left(\hat{v}_{\text {vessel }} / \hat{u}_{\text {vessel }}\right) \in\left(-90^{\circ},+90^{\circ}\right)$.

In the rare case that both $\hat{u}_{\text {vessel }}=0$ and $\hat{v}_{\text {vessel }}=0$, the previous direction is maintained.

\footnotetext{
${ }^{1}$ Data not shown. The testing algorithm is part of the free software package available online.
}

\section{Technological development and field experience}

To apply the strategy described in the previous section, we developed software that solves the equation system [Eq. (2)] and provides in real time the direction $\hat{\alpha}$ and the distance $\hat{d}$ through a user-friendly graphical interface. 


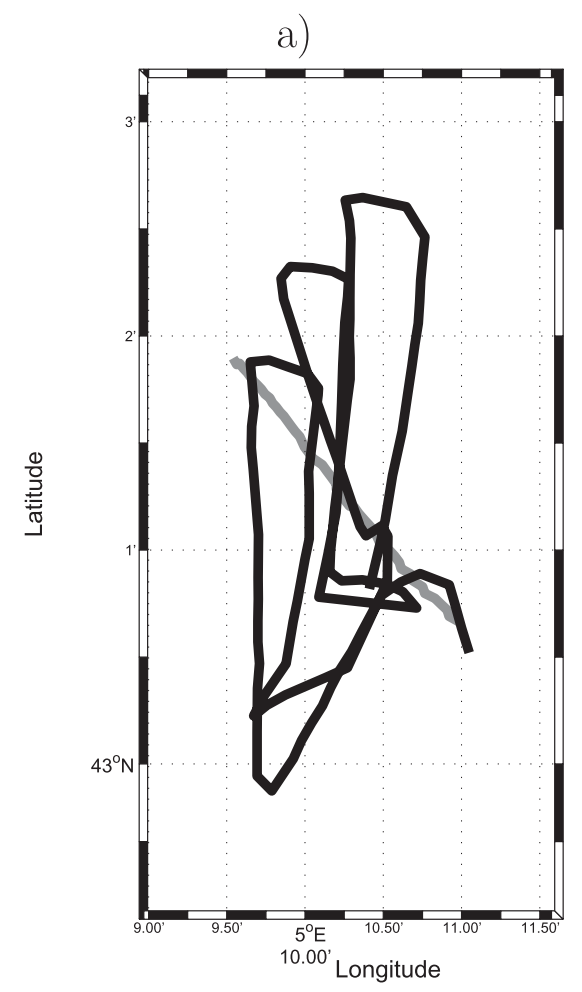

b)

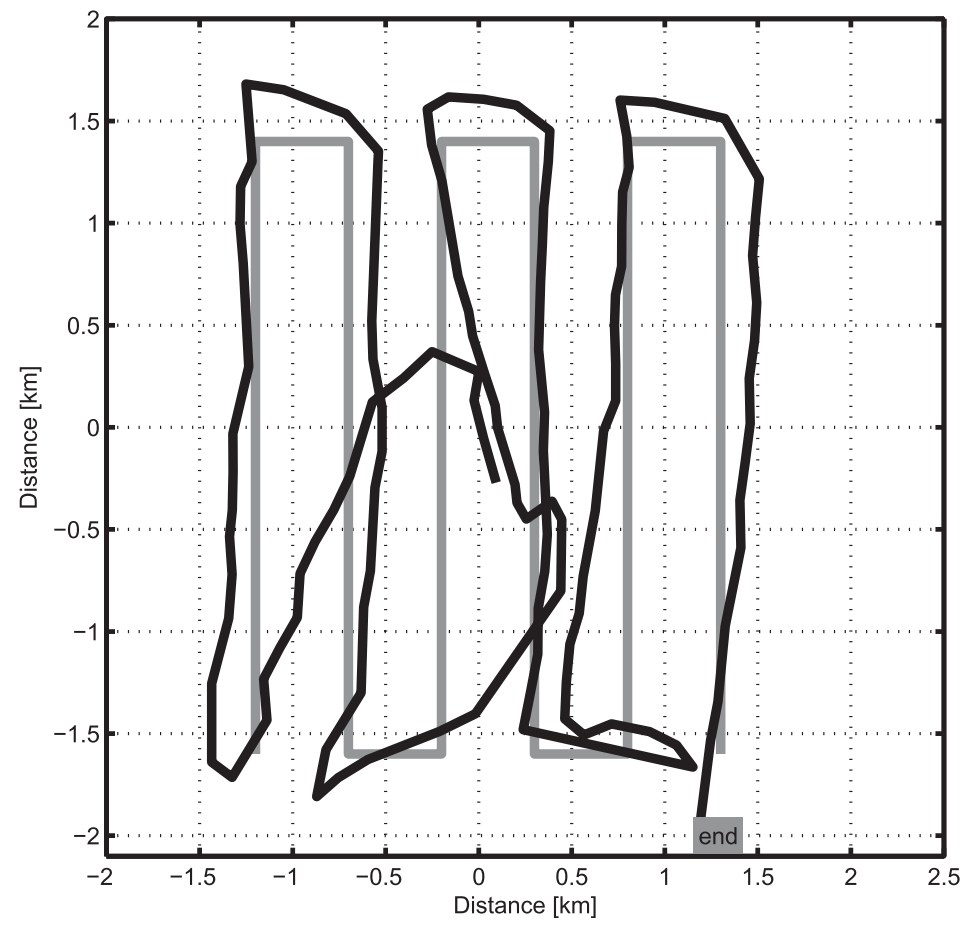

FIG. 2. Radiator test during the Latex00 cruise. (a) Vessel (black) and buoy (gray) tracks in geographical coordinates. Tracking of the ship route begins at the time of deployment of the reference buoy. (b) Expected (gray) and obtained (black) vessel tracks in the Lagrangian reference frame. End of the ship route is indicated. The first part of the ship route corresponds to the vessel repositioning from the point of deployment of the reference buoy to the beginning of the radiator shape. Large discrepancies are observed at most turn points, in particular at $(-0.2,-1.6)$ and $(0.8,-1.6)$. 
a)

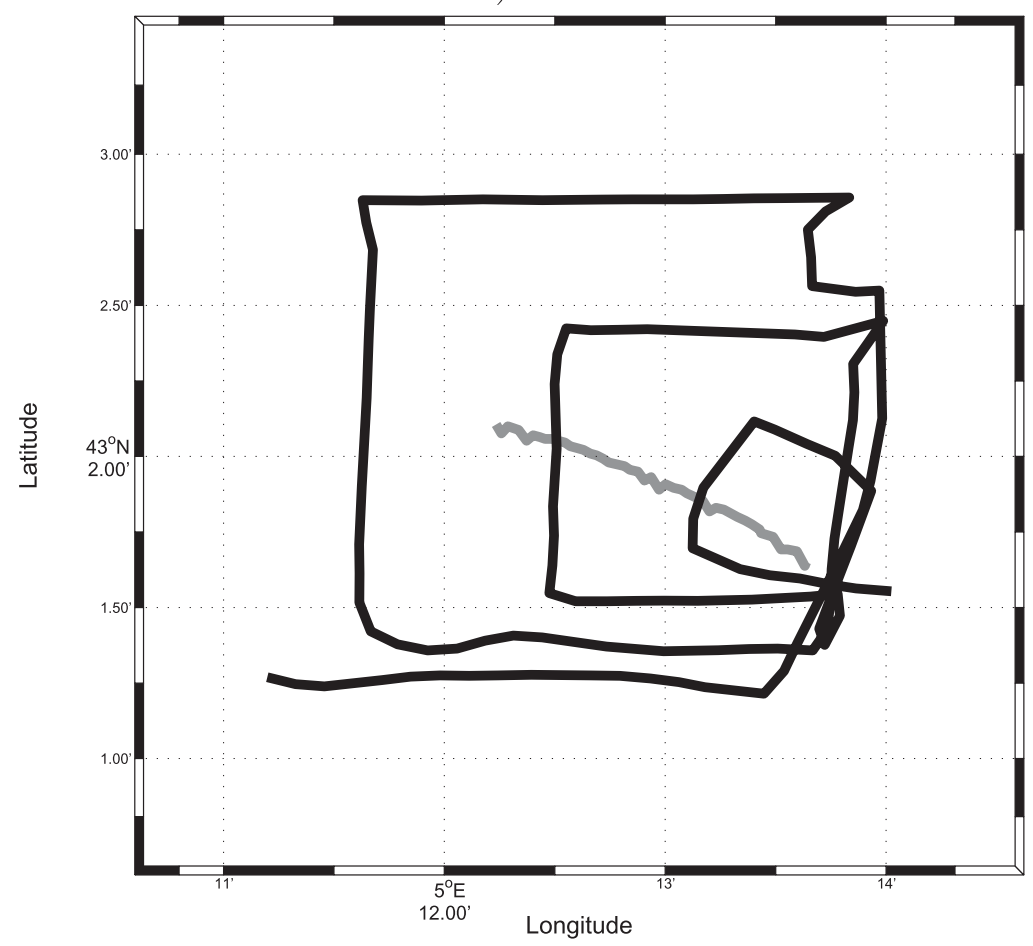

b)

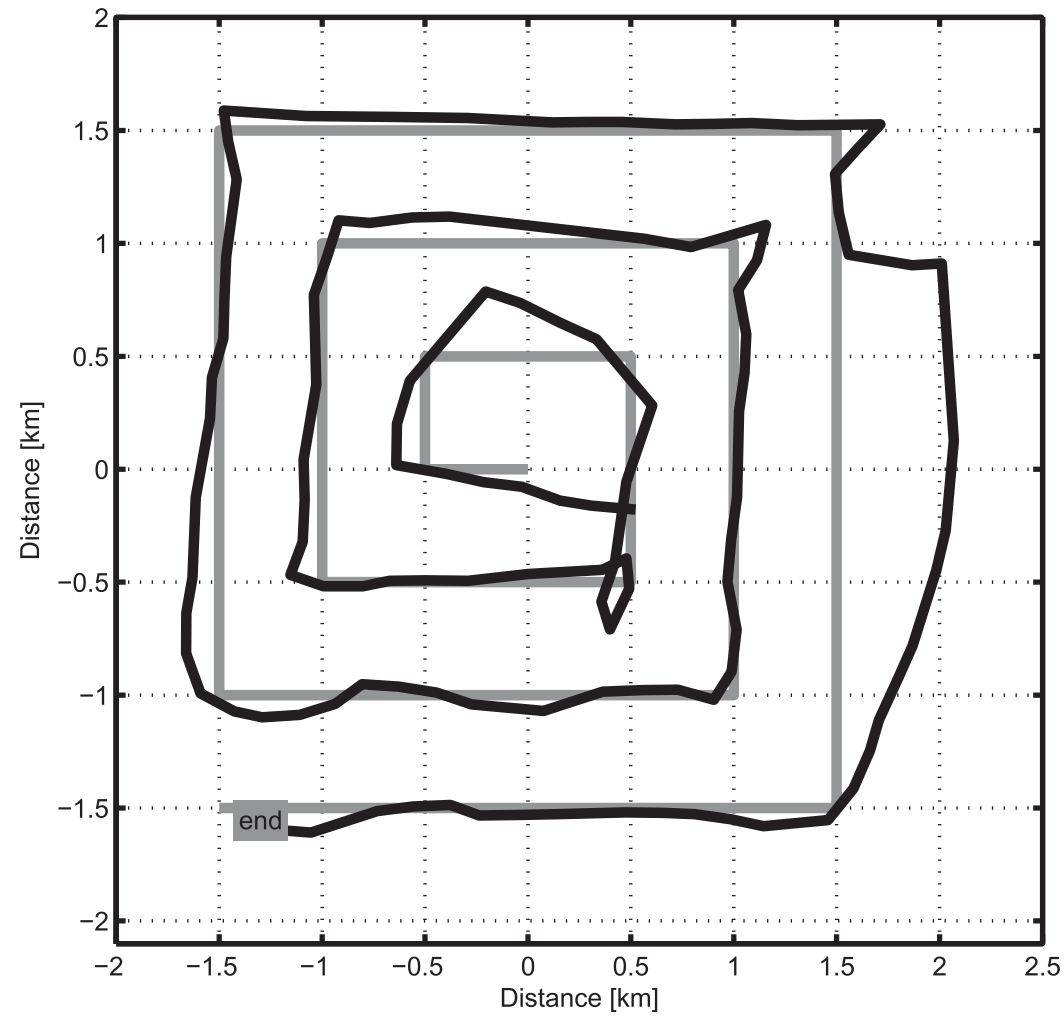

FIG. 3. As in Fig. 2, but for the expanding square spiral test during the Latex00 cruise. Discrepancies are again observed near turn points $(-0.5,0.5),(0.5,-0.5),(1,1)$, and $(1.5,1.5)$. 
The scientist in charge of the Lagrangian navigation can then communicate this information to the bridge to update the ship route.

One of the key aspects for the implementation of the software consists is knowing, in due time, both the position of the vessel and that of the reference buoy. The vessel position can be easily acquired at very high frequency from the onboard positioning system. On the other hand, the reference buoy position needs to be transmitted on board. Three different transmission systems between the ship and the reference buoy have been considered: HF/VHF radio, Argos, and Iridium.

The HF/VHF solution has been excluded because, despite its potential long-range performance, the required large size of the antenna mounted on the buoy would have influenced its drifting. Indeed, during IronEx, Coale et al. (1998) reported that the buoy extended about $2 \mathrm{~m}$ above sea level and, thus, a daily correction based on the tracer concentration itself had to be applied for wind and current effects (Stanton et al. 1998).

The Argos solution has been adopted for the first tests at sea during the Latex00 cruise offshore of Marseille (Fig. 1). Our setup included a receiver board Martec RMD03 and an external antenna in order to allow direct communication between the reference buoy and the vessel. In fact, the standard Argos satellite communication would not have provided the reference buoy positions rapidly enough because of the system procedure for data processing and transmission. Although a range of 5 miles was expected, it was only possible to obtain a communication range of 1 mile. This was probably because the receiver, despite being positioned as high as possible on the mast, was only $10 \mathrm{~m}$ above sea level. Such range would have posed a strong limitation to the extension of the conservative tracer release and samplings. Thus, the Argos transmission system was rejected for the field campaigns listed below. Nonetheless, this configuration allowed us to test the software development and to validate the method. In particular, during Latex00, we tested the software by performing two routes of different shapes: a radiator and an expanding square spiral. The radiator is the route shape most frequently cited in literature. It was adopted during the IronEX (Coale et al. 1998), PRIME (Law et al. 2001), SEEDS, and SEEDS II (Tsumune et al. 2005, 2009) experiments. The expanding square spiral was instead adopted during SERIES (Law et al. 2006). During SOIREE (Boyd and Law 2001) and CYCLOPS (Law et al. 2005), an expanding hexagon route was also used, but we considered such a shape too complex. In fact, with respect to the expanding square spiral, the expanding hexagon route has $50 \%$ more turn points (six instead of four for every cycle) without any theoretical

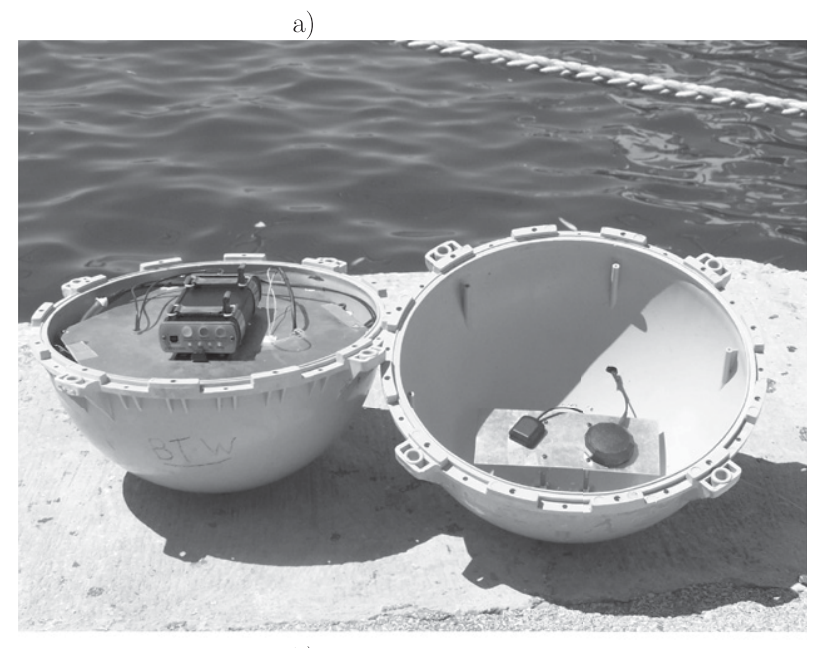

b)

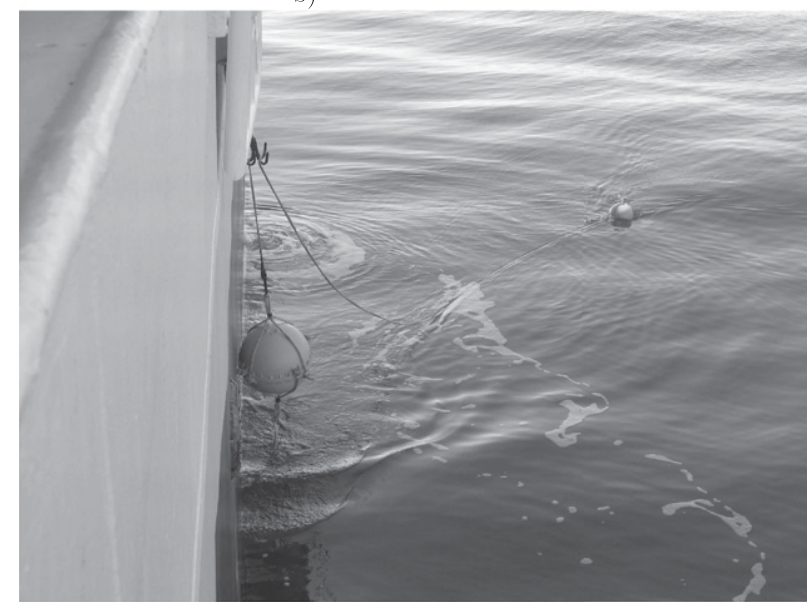

FIG. 4. Pictures of the prototype buoy. (a) Iridium transmitter/ receiver inside the buoy. (b) Recovery of the buoy during the Latex10 cruise. The lifeline and the small float were added to facilitate deployment and recovery operations.

advantage. As an example, the Lagrangian-corrected route presented by Law et al. (2005) in their Fig. 1c appears very irregular.

During the first test of Latex00 (radiator route), the drift of the reference buoy, equipped with a 6-m-long holeysock drogue centered at $15-\mathrm{m}$ depth, was essentially northwestward, with a velocity on the order of $0.1 \mathrm{~m} \mathrm{~s}^{-1}$ (Fig. 2a). The Lagrangian-corrected ship track shows good agreement with respect to the expected route. Nevertheless, we observed large discrepancies at most turn points (Fig. 2b). Indeed, the Argos time interval of communication was still quite large (about $15 \mathrm{~min}$ ). Therefore, it did not provide sufficient information nearby the turn points to supply the new ship direction in due time.

During the second test of Latex00 (expanding square spiral route), the software worked quite well, although uncertainties appeared again nearby the turn points 


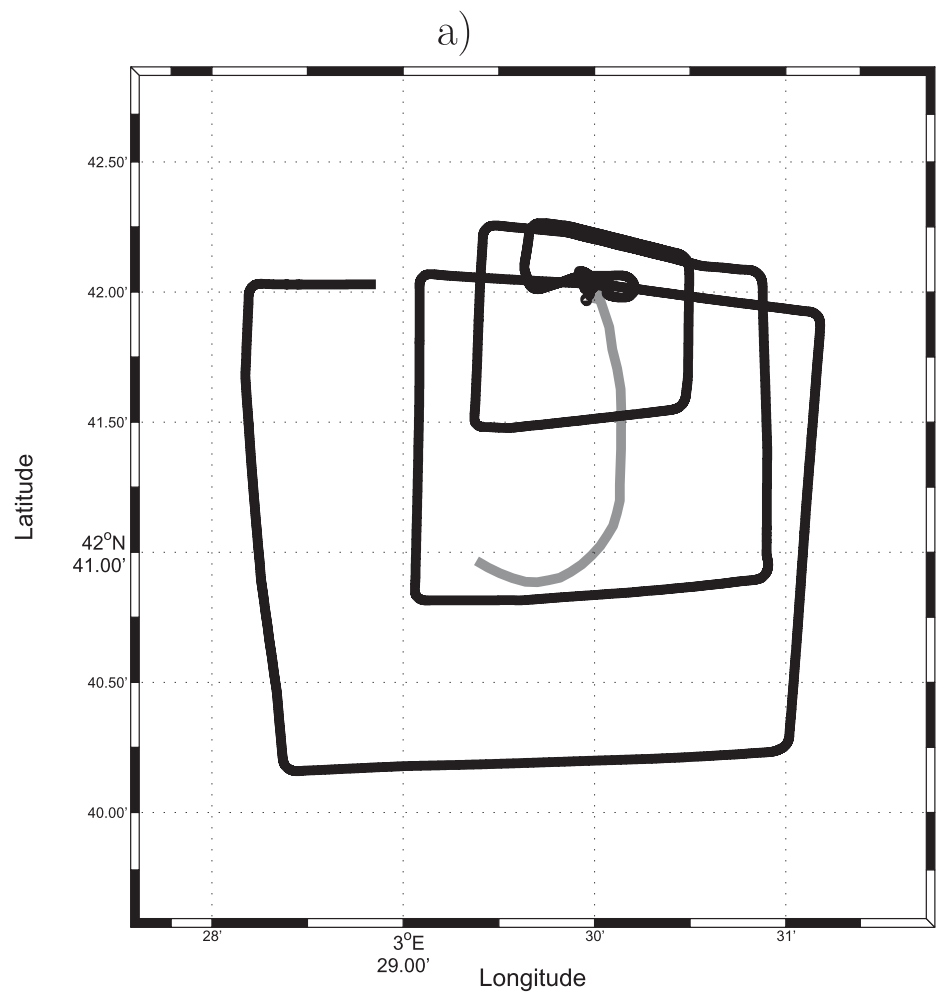

b)

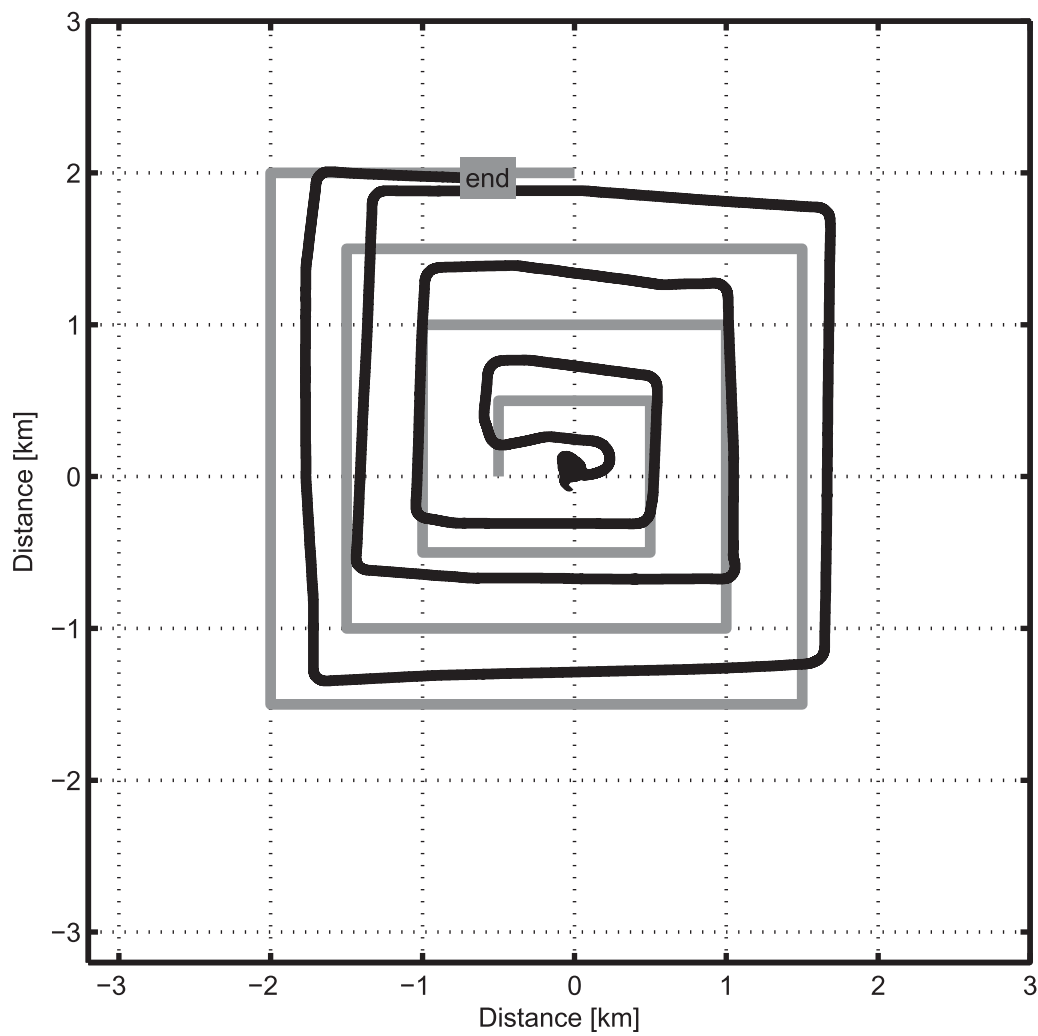

FIG. 5. As in Fig. 2, but for the 6-h test during the Latex10 cruise. Northwest shift of the Lagrangian-corrected route was due to a bug in the first version of the code (see text). 


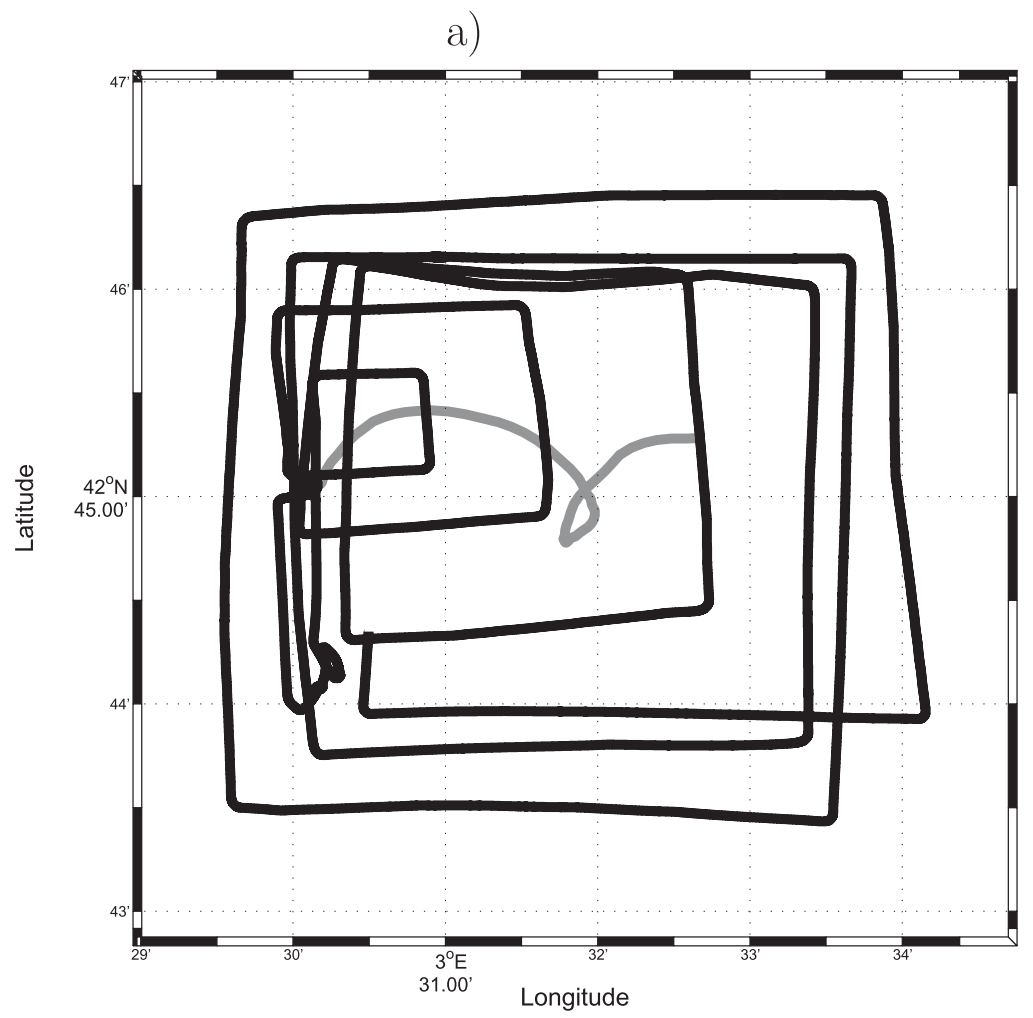

b)

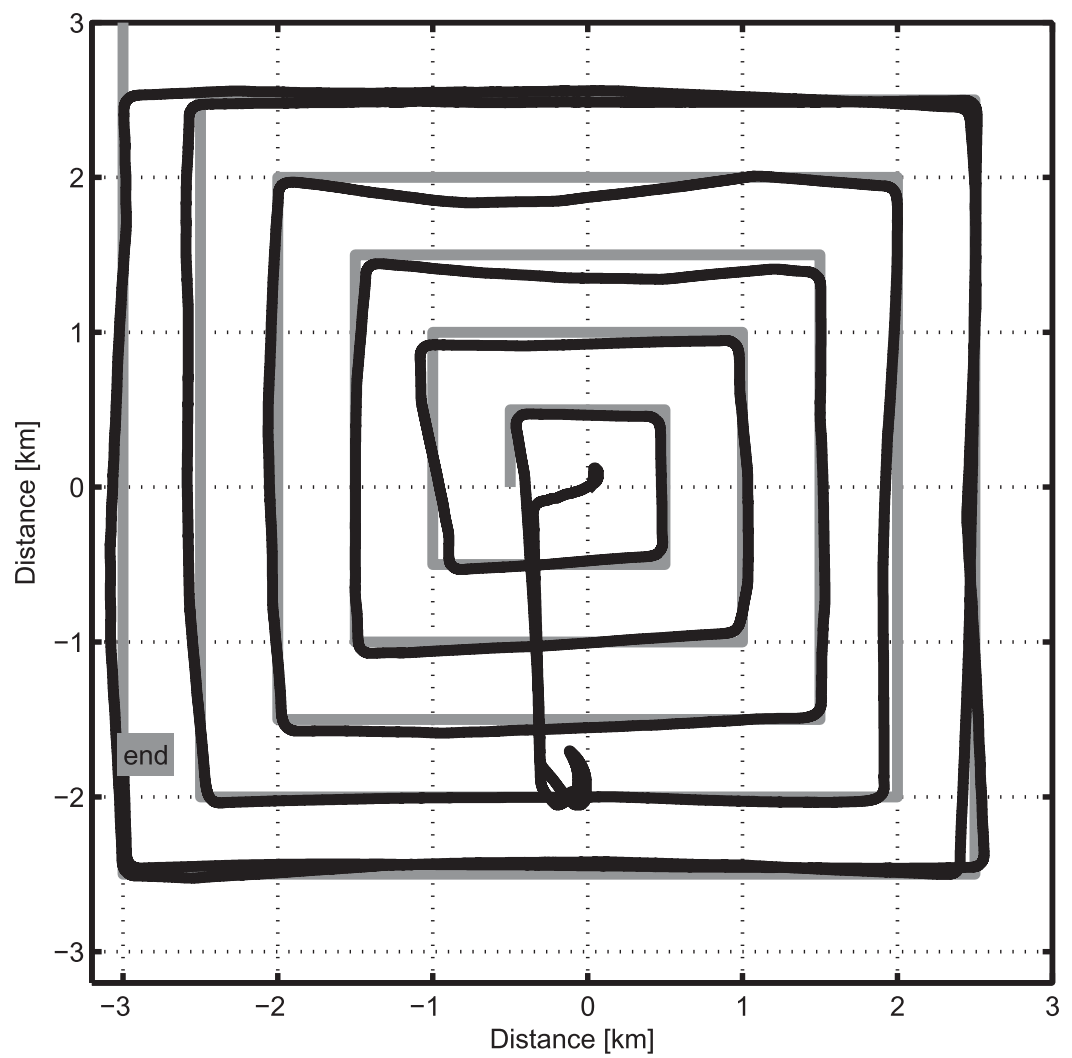

FIG. 6. As in Fig. 2, but for the tracer release during the Latex10 cruise. 
(Fig. 3). Nevertheless, this latter shape turned out to be easier to follow because of the increasing time interval between successive turn points. Another advantage is that the route can begin at the deployment position of the reference buoy. Hence, the expanding square spiral route was chosen for the Latex10 cruise.

The signal range and communication delay problems of the Argos system described above led us to take into consideration the Iridium transmission system. The Iridium network covers the whole earth thanks to a satellite constellation mainly used for hand-held phone communications. In 2007, at the beginning of our project some manufacturers were beginning to develop Iridium buoys. Indeed, MetOcean provided Iridium Surface Velocity Program (SVP) drifters. Nevertheless, (i) the MetOcean buoys sent data once per hour, (ii) the transmission frequency was not adjustable, (iii) there was no receiver to receive messages directly on board, and (iv) there was no possibility to remotely change the buoy setup. Therefore, we decided to develop our own prototype buoy with an Iridium transmitter/receiver (Fig. 4). This system was developed by e-Track (http://e-track.ect-industries.fr) ${ }^{2}$ and consists of a bidirectional satellite telephone system, which allows for worldwide communication and transmits data as short burst data (SBD; somewhat equivalent to the short message system of mobile phones). The SBD are transmitted via satellite from the buoy to an onshore station that, in turn, transfers the information via satellite to the vessel. The time interval between the buoy emission and the onboard reception is certified to be less than $1 \mathrm{~min}$ in $99 \%$ of the cases. This way, we obtained a buoy extremely compact with a worldwide range of transmission and a frequency of communication practically only limited by cost and/or battery life.

This system has been used during the Latex10 cruise. We equipped the prototype buoy with a 6-m-long holeysock drogue centered at $11.5-\mathrm{m}$ depth. Before the tracer release, we performed a 6-h test, during which the reference buoy moved initially southward and then westward (Fig. 5a). The Iridium communication worked well and the delay problems at turn points were greatly reduced (Fig. 5b). Nevertheless, thanks to the higher precision obtained, we identified a bug in the code, generating a northwestward shift of the route with respect the theoretical spiral. We were able to rapidly fix it.

Finally, during the $\mathrm{SF}_{6}$ release, the software worked very well. Although the reference buoy followed a more complicated trajectory than the previous tests (Fig. 6a), the Lagrangian-corrected ship track was in very good

\footnotetext{
${ }^{2}$ The e-Track brand, now part of NSE Industries, specializes in tracking solutions and data transmission.
}

agreement with the expected route (Fig. 6b). The initial deviation from the expected spiral is only due to the ship drift during the setup of the $\mathrm{SF}_{6}$ release device after the deployment of the reference buoy, while the second turn around the last spiral branch is due to the deployment of several Argos buoys around the $\mathrm{SF}_{6}$ patch.

\section{Concluding remarks}

This paper intends to present a method to perform vessel routes in a Lagrangian reference frame for in situ tracer experiments. With respect to previous works, we describe in detail our theoretical approach based on a simple system of ballistic equations. Moreover, we report the tests we performed on different communication systems between the buoy marking the water mass and the research vessel. Such tests lead to the development of a prototype buoy with the bidirectional worldwiderange Iridium communication system. The software developed to manage the Lagrangian navigation worked very well during the Latex10 cruise and allowed for the release of the passive tracer in a square patch very precisely. Such a software is equipped with a series of graphical and user-friendly accessories for (i) planning in near-real time the vessel route and sampling stations, (ii) treating and mapping oceanographic cruise data, and (iii) simulating tracer injection and dispersion in idealized conditions by a Lagrangian single-particle numerical model. The entire package for MATLAB is distributed in the hope that it will be useful for the oceanographic community and it can be freely downloaded (from http:// mio.pytheas.univ-amu.fr/ $\sim$ doglioli).

Future foreseeable developments include the possibility to take more advantage of the bidirectional Iridium communication, by implementing an automatic position query to the reference buoy when the vessel is near turn points. Moreover, as already mentioned in section 2, multibuoy marking of the water mass could also be considered for (i) a more precise positioning of the center of the Lagrangian reference frame and (ii) an estimation of rotation and stirring effects of the investigated water mass.

Acknowledgments. The LATEX project is supported by the programs LEFE/IDAO and LEFE/CYBER of the CNRS/INSU and by the Region PACA. We thank the crews of the R/V Le Suroit and the R/V Téthys II, and all the LATEX collaborators.

\section{REFERENCES}

Boyd, P. W., and C. S. Law, 2001: The Southern Ocean Iron Release Experiment (SOIREE) -Introduction and summary. DeepSea Res. II, 48, 2425-2438, doi:10.1016/S0967-0645(01)00002-9. 
Campbell, R., F. Diaz, Z. Hu, A. Doglioli, A. Petrenko, and I. Dekeyser, 2013: Nutrients and plankton spatial distributions induced by a coastal eddy in the Gulf of Lion-Insights from a numerical model. Prog. Oceanogr., 109, 47-69, doi:10.1016/ j.pocean.2012.09.005.

Coale, K. H., K. S. Johnson, S. E. Fitzwater, S. P. G. Blain, T. P. Stanton, and T. L. Coley, 1998: IronEx-I, an in situ ironenrichment experiment: Experimental design, implementation and results. Deep-Sea Res. II, 45, 919-945, doi:10.1016/ S0967-0645(98)00019-8.

Conan, P., and C. Millot, 1995: Variability of the northern current off Marseilles, western Mediterranean Sea, from February to June 1992. Oceanol. Acta, 182, 193-205.

Flexas, M. M., X. Durrieu de Madron, M. A. Garcia, M. Canals, and P. Arnau, 2002: Flow variability in the Gulf of Lions during the MATER HFF experiment (March-May 1997). J. Mar. Syst., 33-34, 197-214, doi:10.1016/S0924-7963(02)00059-3.

Hillmer, I., and J. Imberger, 2007: Estimating in situ phytoplankton growth rates with a Lagrangian sampling strategy. Limnol. Oceanogr. Methods, 5, 495-509.

Hu, Z. Y., A. M. Doglioli, A. A. Petrenko, P. Marsaleix, and I. Dekeyser, 2009: Numerical simulations of eddies in the Gulf of Lion. Ocean Modell., 28, 203-208, doi:10.1016/ j.ocemod.2009.02.004.

- A. A. Petrenko, A. M. Doglioli, and I. Dekeyser, 2011a: Numerical study of eddy generation in the western part of the Gulf of Lion. J. Geophys. Res., 116, C12030, doi:10.1029/ 2011JC007074.

,,$-- \ldots$, and $\longrightarrow, 2011 \mathrm{~b}$ : Study of a mesoscale anticyclonic eddy in the western part of the Gulf of Lion. J. Mar. Syst., 88, 3-11, doi:10.1016/j.jmarsys.2011.02.008.

Kersalé, M., A. A. Petrenko, A. M. Doglioli, I. Dekeyser, and F. Nencioli, 2013: Physical characteristics and dynamics of the coastal Latex09 eddy derived from in situ data and numerical modeling. J. Geophys. Res., 118, 399-409, doi:10.1029/ 2012JC008229.

Law, C. S., A. Watson, M. Liddicoat, and T. Stanton, 1998: Sulphur hexafluoride as a tracer of biogeochemical and physical processes in an open-ocean iron fertilisation experiment. Deep-Sea Res. II, 45, 977-994, doi:10.1016/S0967-0645(98)00022-8.

A. Martin, M. Liddicoat, A. Watson, K. Richards, and E. Woodward, 2001: A Lagrangian $\mathrm{SF}_{6}$ tracer study of an anticyclonic eddy in the North Atlantic: Patch evolution, vertical mixing and nutrient supply to the mixed layer. DeepSea Res. II, 48, 705-724.

- E. Abraham, E. Woodward, M. Liddicoat, T. Fileman, T. Thingstad, V. Kitidis, and T. Zohary, 2005: The fate of phosphate in an in situ Lagrangian addition experiment in the eastern Mediterranean. Deep-Sea Res. II, 52, 2911-2927, doi:10.1016/j.dsr2.2005.08.017.

_ , and Coauthors, 2006: Patch evolution and the biogeochemical impact of entrainment during an iron fertilisation experiment in the sub-Arctic Pacific. Deep-Sea Res. II, 53, 2012-2033, doi:10.1016/j.dsr2.2006.05.028.

Nencioli, F., F. d'Ovidio, A. M. Doglioli, and A. A. Petrenko, 2011: Surface coastal circulation patterns by in-situ detection of Lagrangian coherent structures. Geophys. Res. Lett., 38, L17604, doi:10.1029/2011GL048815.

Petrenko, A. A., Y. Leredde, and P. Marsaleix, 2005: Circulation in a stratified and wind-forced Gulf of Lions, NW Mediterranean Sea: In situ and modeling data. Cont. Shelf Res., 25, 7-27, doi:10.1016/j.csr.2004.09.004.

Schaeffer, A., A. Molcard, P. Forget, P. Fraunié, and P. Garreau, 2011: Generation mechanisms for mesoscale eddies in the Gulf of Lions: Radar observation and modeling. Ocean Dyn., 61, 1587-1609, doi:10.1007/s10236-011-0482-8.

Stanton, T., C. Law, and A. Watson, 1998: Physical evolution of the IronEx-I open ocean tracer patch. Deep-Sea Res. II, 45, $947-$ 975, doi:10.1016/S0967-0645(98)00018-6.

Tsumune, D., J. Nishioka, A. Shimamoto, S. Takeda, and A. Tsuda, 2005: Physical behavior of the SEEDS iron-fertilized patch by sulphur hexafluoride tracer release. Prog. Oceanogr., 64, 111-127, doi:10.1016/j.pocean.2005.02.018.

— , and Coauthors, 2009: Physical behaviors of the iron-fertilized patch in SEEDS II. Deep-Sea Res. II, 56, 2948-2957, doi:10.1016/ j.dsr2.2009.07.004. 